\title{
Treatment of gastric epithelial tumours by endoscopic submucosal dissection using an insulated-tip diathermic knife
}

\author{
Xu Li Hua MD, Qian Jun Bo MD, Gu Liu Gen MD, Lu Fei MD, \\ Wang Ya Min MD, Li Yu Ming MD, Lu Hua Sheng MD
}

\begin{abstract}
Xu LH, Qian JB, Gu LG, Lu F, Wang YM, Li YM, Lu HS. Treatment of gastric epithelial tumours by endoscopic submucosal dissection using an insulated-tip diathermic knife. Can J Gastroenterol 2011;25(2):97-101.
\end{abstract}

BACKGROUND: Endoscopic submucosal dissection (ESD) is a promising technique for the treatment of large, pre- and early malignant gastrointestinal lesions.

OBJECTIVE: To assess the rates of en bloc resection, incidence of complications, procedure times and therapeutic outcomes of ESD using an insulated-tip diathermic knife; and to investigate predictors of these outcomes based on the final pathological features of biopsy specimens. METHODS: One hundred twenty patients with endoscopically suspected gastric epithelial tumours who were treated with ESD from January 2006 to December 2009 were evaluated.

RESULTS: The mean diameter of the gastric epithelial tumours in the present cohort was $1.88 \mathrm{~cm}$. The mean diameter of the resected specimens was $3.33 \mathrm{~cm}$. The en bloc resection rate was 90\% (108 of 120). The median length of the operation was $64.6 \mathrm{~min}$. The bleeding and perforation complication rates were $5.0 \%$ (six of 120 ) and $2.5 \%$ (three of 120), respectively. Of 10 gastric tumours initially diagnosed as adenocarcinoma on biopsy, four were found to be low-grade dysplasia and six were found to be high-grade dysplasia after resection and final pathological examination. A total of $112(93.33 \%)$ patients underwent curative treatment, eight patients $(6.67 \%)$ underwent noncurative treatment with ESD, and two patients (1.67\%) experienced local recurrence and subsequently underwent surgery.

CONCLUSIONS: ESD is a promising local curative treatment option for gastric epithelial tumours, but still carries the risks of bleeding and/or perforation. Differences in the interpretation of histological results among different pathologists and/or between biopsy specimens before ESD and the en bloc tissue specimens after ESD will result in discrepancies.

Key Words: Endoscopic submucosal dissection; Gastric epithelial tumour; IT knife

ndoscopic mucosal resection (EMR) of early gastric cancer (EGC)

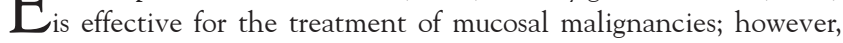
one-piece (ie, 'en bloc') resection is often not achieved using conventional EMR (1). It remains difficult to remove a gastroesophageal lesion with ulceration and/or submucosal fibrosis that is greater than $2 \mathrm{~cm}$ in diameter. Endoscopic submucosal dissection (ESD) techniques using a variety of knives, such as the insulated-tip diathermic (IT) knife, hook knife or flex knife, have been developed in Japan $(2,3)$, with high one-piece resection rates being reported (1,3). An algorithm for ESD of gastric neoplasms is presented in Figure 1. The purpose of the present study was to evaluate the effectiveness of IT knife ESD for early gastric cancer.

\section{Le traitement des tumeurs épithéliales gastriques par dissection sous-muqueuse endoscopique au moyen d'un couteau diathermique à pointe isolée}

HISTORIQUE : La dissection sous-muqueuse endoscopique (DSE) est une technique prometteuse pour traiter les grosses lésions gastrointestinales prétumorales ou présentant une malignité précoce.

OBJECTIF : Évaluer les taux de résection en bloc, l'incidence de complications, le temps d'intervention et les issues thérapeutiques de la DSE au moyen d'un couteau diathermique à pointe isolée et étudier les prédicteurs de ces issues d'après les caractéristiques pathologiques définitives des échantillons de biopsie.

MÉTHODOLOGIE : Les chercheurs ont évalué 120 patients ayant une tumeur épithéliale gastrique présumée à l'endoscopie et qui ont été traités par DSE entre janvier 2006 et décembre 2009.

RÉSULTATS : Les tumeurs épithéliales gastriques de la présente cohorte avaient un diamètre moyen de $1,88 \mathrm{~cm}$. Les échantillons réséqués avaient un diamètre moyen de $3,33 \mathrm{~cm}$. Le taux de résection en bloc s'élevait à 90 \% (108 sur 120). L'opération avait une durée médiane de 64,6 minutes. Les taux de saignements et de complications par perforation correspondaient à 5,0\%( six sur 120$)$ et à 2,5\%(trois sur 120$)$, respectivement. Sur les dix tumeurs gastriques d'abord diagnostiquées comme des adénocarcinomes à la biopsie, quatre étaient plutôt des dysplasies bénignes et six, des dysplasies graves après résection et examen pathologique final. Au total, $112(93,33 \%)$ patients ont subi un traitement curatif, huit $(6,67 \%)$ un traitement non curatif par DSE, et deux $(1,67 \%)$ ont vécu une récurrence locale, puis ont subi une opération.

CONCLUSIONS : La DSE est une option thérapeutique localisée prometteuse contre les tumeurs épithéliales gastriques, mais s'associe encore aux risques de saignement ou de perforation. Les différences dans l'interprétation des résultats histologiques entre les divers pathologistes ou les divers échantillons de biopsie avant la DSE et les échantillons de tissu en bloc après la DSE entraîneront des écarts.

Department of Gastroenterology, The First People's Hospital of Nantong, Jiangsu, People's Republic of China

Correspondence: Dr Xu Li Hua, Department of Gastroenterology, The First People's Hospital of Nantong, Jiangsu, 226001, People's Republic of

China. Telephone 86-0513-85061285, fax 86-0513-85061003, e-mail xlh1118@yahoo.com.cn

Received for publication May 23, 2010. Accepted June 7, 2010 


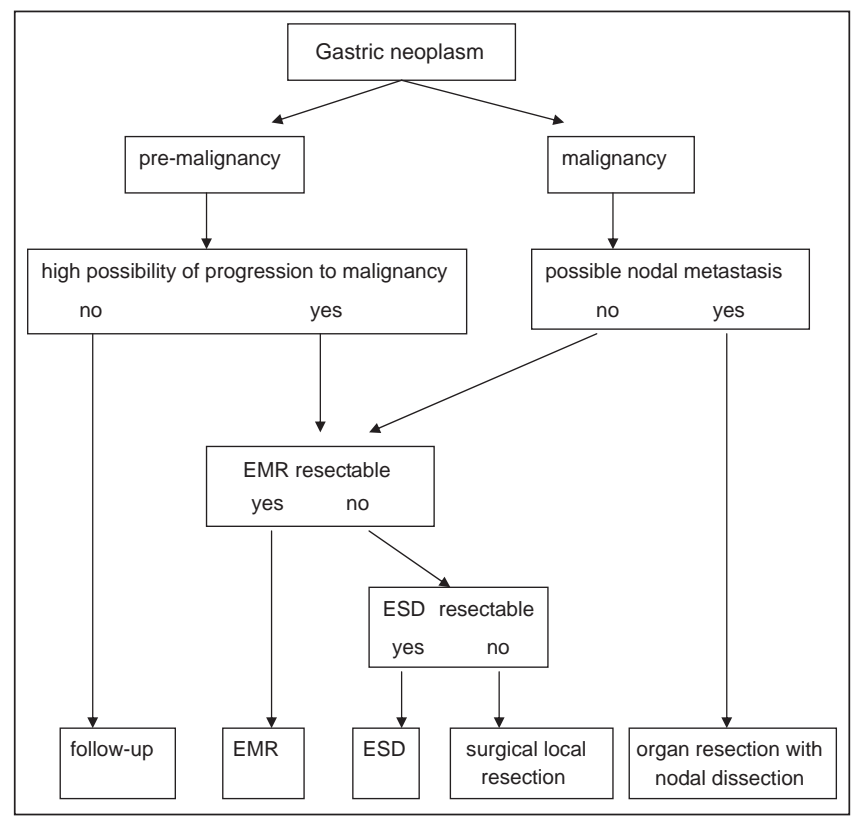

Figure 1) Algorithm for endoscopic submucosal dissection (ESD) of gastric neoplasms. EMR Endoscopic mucosal resection

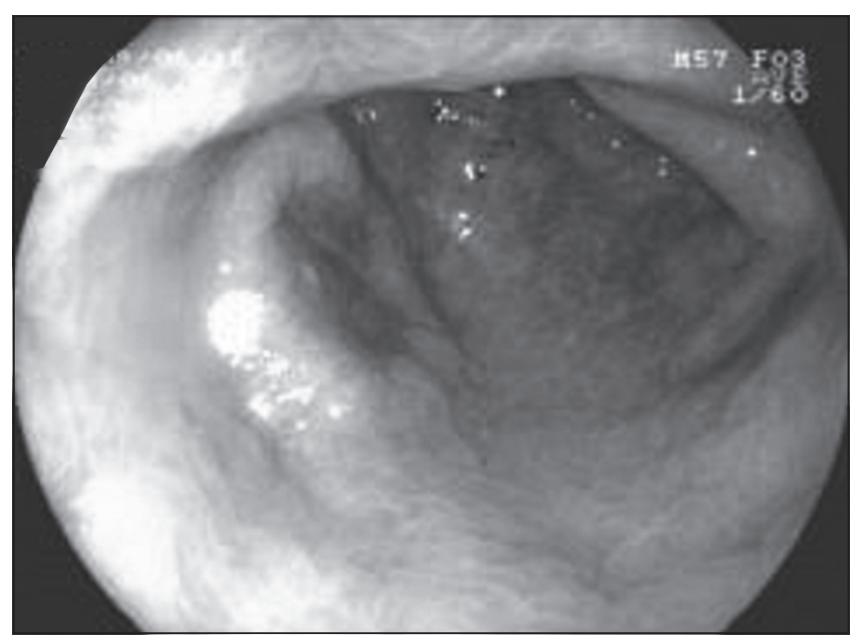

Figure 2) Narrow band imaging demonstrating a $2 \mathrm{~cm} \times 1 \mathrm{~cm} \mathrm{IIa+IIc}$ gastric epithelial tumour at the anterior wall of the gastric antrum

\section{Instruments}

The instruments used for ESD included a single-channel endoscope (GIF-Q260, Olympus, Japan) and accessories, an IT knife (KD 610L) and needle knife (KD-1L-1) (Olympus, Japan), and an ICC-200 electrosurgical unit (ERBE, Germany). A hood (D-201-11802, Olympus, Japan) was attached to the tip of the endoscope for the ESD procedure.

\section{Procedure}

The ESD procedure was performed similarly in all 120 patients. A representative patient with EGC resected using ESD is described herein. Before ESD, chromoendoscopy was performed using $0.2 \%$ indigo carmine to demarcate the margin of the EGC. Several areas were marked at $5 \mathrm{~mm}$ to $10 \mathrm{~mm}$ outside the margin of the EGC using a needle knife to ensure a cancer-free margin. Using a 23-gauge disposable injector, $1 \mathrm{~mL}$ to $4 \mathrm{~mL}$ of normal saline with $0.0025 \%$ adrenaline was subsequently injected into the submucosa to lift the lesion. Initially, a circumferential incision was made, followed by submucosal dissection with an IT knife (Figures 2 to 6). Following ESD, a standard-dose proton pump inhibitor was administered intravenously to all patients for six days.

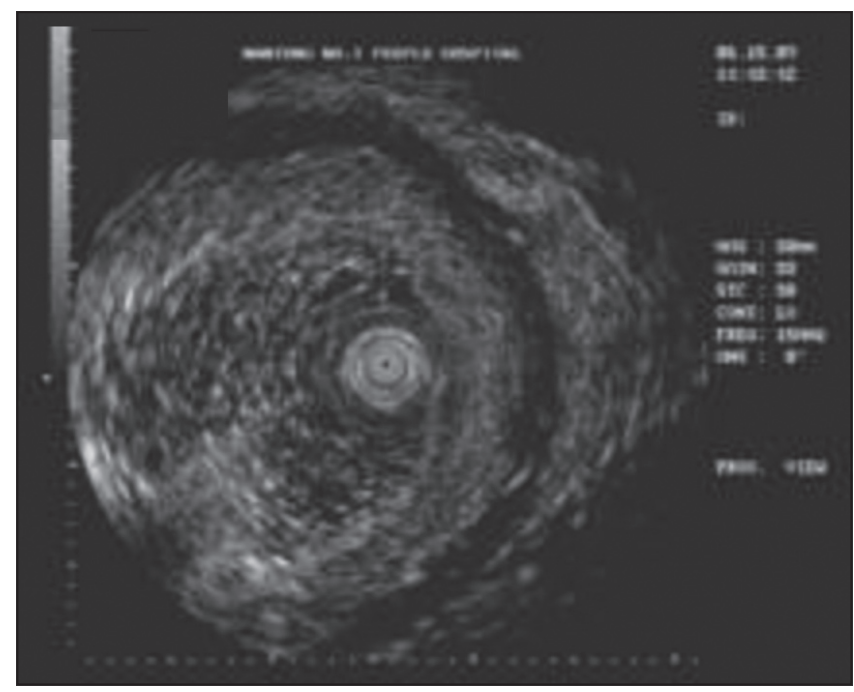

Figure 3) Endoscopic ultrasonography showing the tumour limited to the mucosal layer

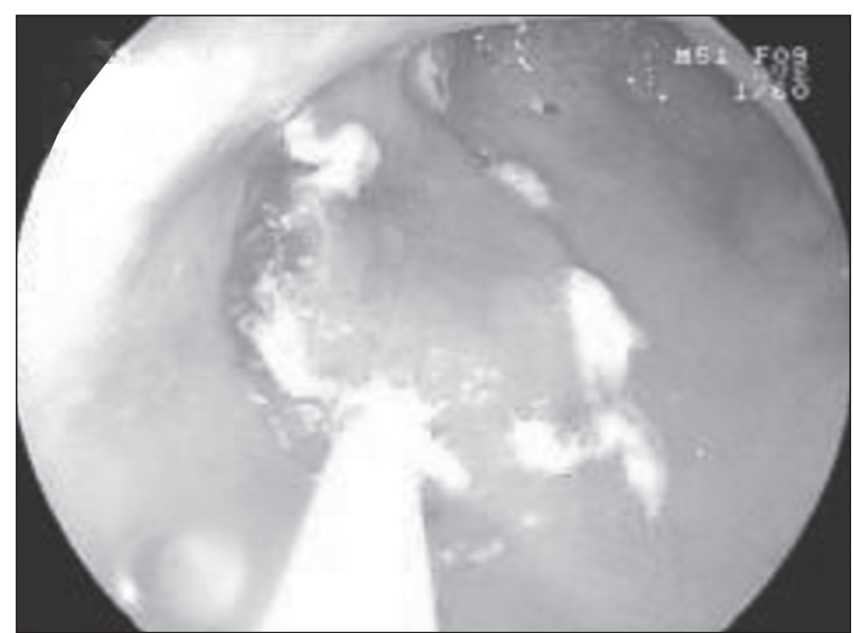

Figure 4) Several areas $5 \mathrm{~mm}$ to $10 \mathrm{~mm}$ outside the margin of the early gastric cancer were marked

Tumour location was classified as being in the upper, middle or lower one-third of the stomach (5). One-piece resection was defined as 'en bloc' resection. Resection was considered to have a tumour-free margin when the vertical and horizontal margins were free of tumour cells.

Resected specimens were fixed on a board with pins and cut into $2 \mathrm{~mm}$ slices according to the Japanese classification of gastric carcinoma (5). All specimens were evaluated histologically according to whether tumorous glandular tissue was present at the margin of each slice. Histopathological diagnosis was based on criteria proposed by the WHO (Figures 7 and 8).

\section{Complications of ESD}

Complications including massive bleeding and perforation were recorded following ESD. Massive bleeding was defined as blood loss of greater than $500 \mathrm{~mL}$ or hemoglobin loss of greater than $20 \mathrm{~g} / \mathrm{L}$. Perforation was diagnosed when other organs, extraluminal fat or the extraluminal space were observed endoscopically through the muscle layer during ESD, irrespective of the presence of air accumulation in the abdomen, retroperitoneum or mediastinum.

\section{Residual and recurrent tumours following ESD}

Endoscopic re-examination was performed every two to three months during the first year following ESD, every six months during the second year and annually thereafter. In each endoscopic follow-up 


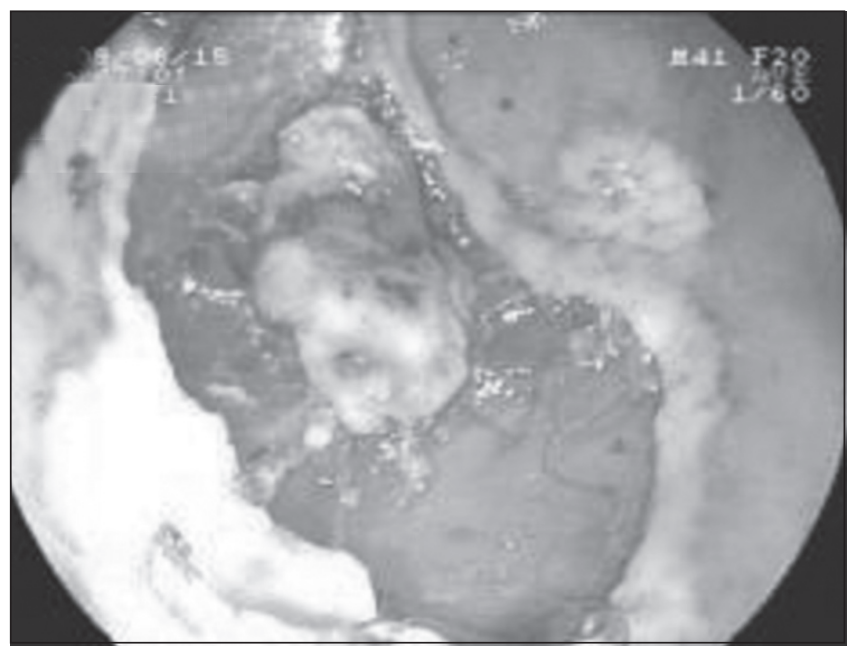

Figure 5) Circumferential incision of the gastric epithelial tumour

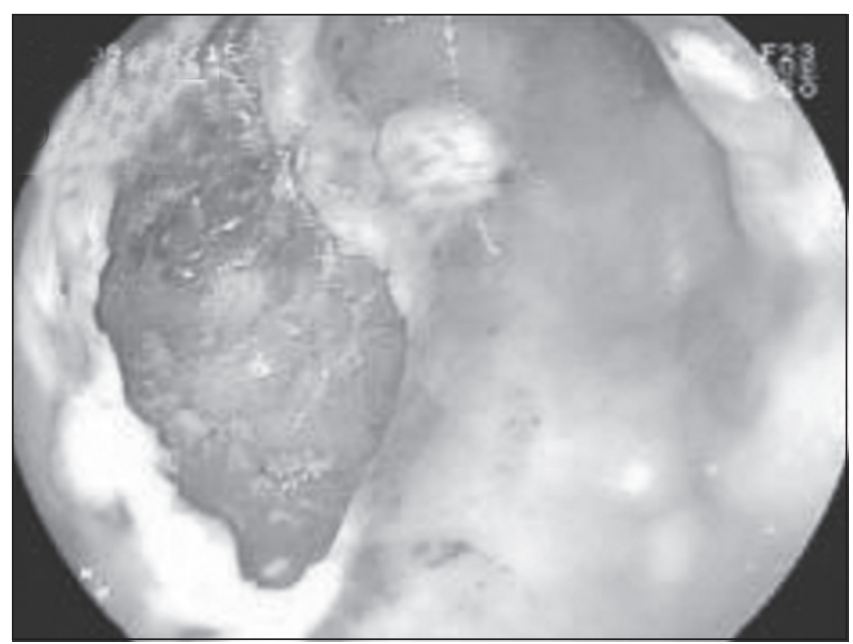

Figure 6) A $3.5 \mathrm{~cm} \times 1.5 \mathrm{~cm}$ mucosal defect after endoscopic submucosal disection

session, endoscopic biopsies were routinely taken from the surrounding areas of previous ESD and/or any suspicious lesions nearby for subsequent histological examination to identify any residual or recurrent cancer.

\section{RESULTS}

A total of 120 patients underwent ESD for gastric epithelial tumours; their demographic characteristics are presented in Table 1 . There were 72 men and 48 women with a mean $( \pm$ SD) age of $51.5 \pm 14.6$ years (range 26 to 75 years). The majority of the tumours were located in the middle $(n=24)$ and lower $(n=90)$ one-third of the stomach. The majority of the tumours were classified as flat, elevated, superficial cancer type IIa $(n=54)$ and IIa+IIc $(n=45)$ according to endoscopic morphological classification. The mean diameter of the tumours was $1.88 \pm 0.85 \mathrm{~cm}$, while the mean diameter of the resected specimens was $3.33 \pm 1.18 \mathrm{~cm}$. The depth of the EGC was evaluated after pathological assessment: 108 tumours were limited to the mucosal layer, eight to the submucosal superficial layer (less than $500 \mu \mathrm{m}$ from the muscle layer) and four to the deep submucosal layer. According to the final pathological classification, the majority of EGCs resected were high-grade dysplasia $(n=48)$ and well-differentiated adenocarcinoma $(n=35)$. However, there were 27 tumours with low-grade dysplasia, six with moderately differentiated adenocarcinoma and four with poorly differentiated adenocarcinoma resected by ESD. Of the 10 gastric tumours initially diagnosed as adenocarcinoma on biopsy, four were found to be

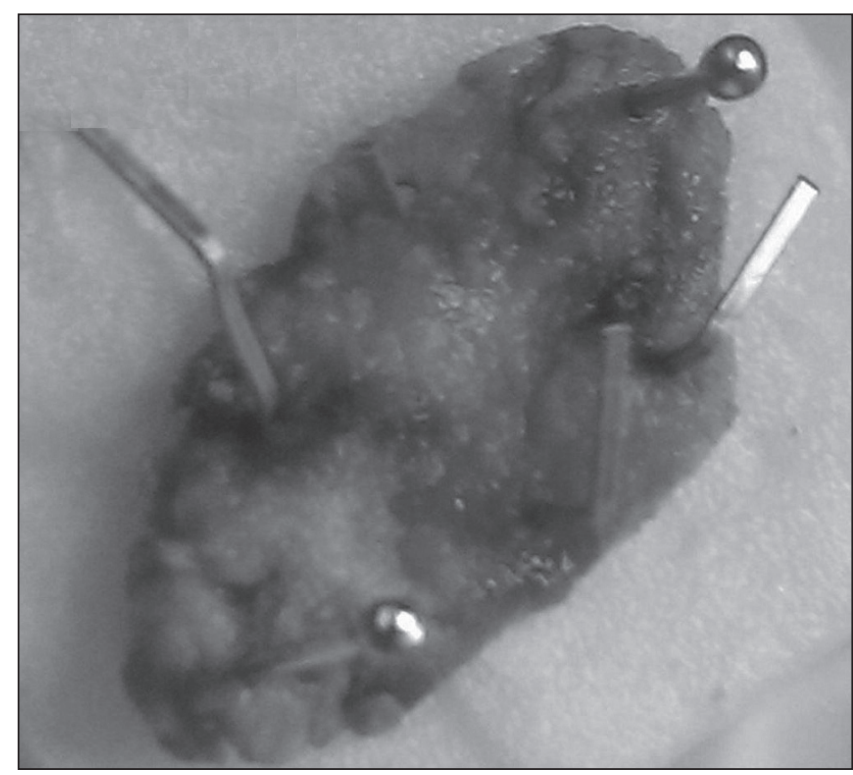

Figure 7) A $3.4 \mathrm{~cm} \times 1.5 \mathrm{~cm}$ resected specimen fixed on a board with pins

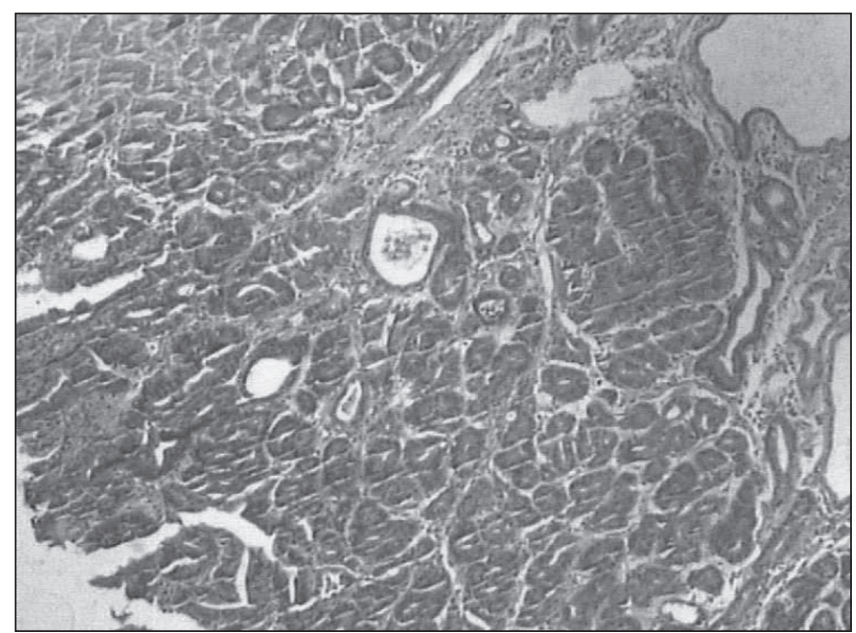

Figure 8) Pathology showing a well-differentiated intramucosal cancer (hematoxylin and eosin stain, original magnification $\times 40$ )

low-grade dysplasia and six were found to be high-grade dysplasia after resection and final pathological examination. Two gastric tumours initially diagnosed as high-grade dysplasia on biopsy were found to be well-differentiated adenocarcinomas.

The en bloc resection rate with tumour-free margins was 90\% (108 of 120). There were 12 patients in whom en bloc resection failed, three patients experienced perforation, four patients with the tumour located at the posterior wall of the gastric antrum, three patients with the tumour located at the posterior wall of the middle gastric body and two patients with the tumour located near the cardia. The median operation time was $64.6 \mathrm{~min}$ (range 30 to $120 \mathrm{~min}$ ). The median length of hospital stay was 10.5 days (range seven to 28 days).

The complications and local recurrence following ESD are summarized in Table 2. Six patients $(5.0 \%)$ experienced massive bleeding during ESD, and none (0\%) required a blood transfusion. The amount of blood loss from any patient did not exceed $700 \mathrm{~mL}$, and the mean hemoglobin loss among patients was approximately $20 \mathrm{~g} / \mathrm{L}$. Three patients $(2.5 \%)$ experienced complications of perforation during ESD and were subsequently referred for emergency surgery. Among these, one patient with an upper gastric tumour and two with lower gastric tumours experienced perforation after ESD. 


\begin{tabular}{lc} 
TABLE 1 \\
Demographic characteristics of $\mathbf{1 2 0}$ patients with gastric \\
epithelial tumours who underwent endoscopic submucosal \\
dissection & \\
\hline Age, years (mean $\pm \mathrm{SD}$ [range]) & $51.5 \pm 14.6(26-75)$ \\
Sex, $\mathrm{n}$ (male/female) & $72 / 48$ \\
Tumour location (upper third/middle third/lower third), $\mathrm{n}$ & $6 / 24 / 90$ \\
Tumour gross appearance (I/lla/llb/llc/lla+IIc), $\mathrm{n}$ & $10 / 54 / 4 / 7 / 45$ \\
Tumour size, cm (mean $\pm \mathrm{SD}$ [range]) & $1.88 \pm 0.85(0.8-3.0)$ \\
Resected specimen size, cm (mean $\pm \mathrm{SD}$ [range]) & $3.33 \pm 1.18(1.3-6.0)$ \\
Tumour depth (mucosa/submucosa), $\mu \mathrm{m}$ & $108 / 12$ \\
Tumour pathology, $\mathrm{n}$ & \\
Low-grade dysplasia & 27 \\
High-grade dysplasia & 48 \\
Well-differentiated adenocarcinoma & 35 \\
Moderately differentiated adenocarcinoma & 6 \\
Poorly differentiated adenocarcinoma & 4 \\
\hline
\end{tabular}

Curative treatment was defined as tumour-free margins including lateral and vertical margins, no lymphovascular involvement and tumour depth limited to the submucosal superficial layer (less than $500 \mu \mathrm{m}$ from the muscle layer) following pathological assessment. A total of 112 patients $(93.33 \%)$ underwent curative treatment with ESD for gastric epithelial tumours. Eight patients (6.67\%) underwent noncurative treatment with ESD. Five of these eight patients had a vertical margin associated with cancer and three had submucosal deep cancer. These five patients were advised to undergo additional surgery, but they all refused because of major systemic comorbid conditions such as congestive heart failure, chronic renal insufficiency or chronic pulmonary insufficiency. Unfortunately, two patients (1.67\%) experienced local recurrence during the follow-up period and subsequently underwent surgery. None of the patients died of gastric cancer-related causes during the follow-up period. All of the patients (100\%) are currently alive.

\section{DISCUSSION}

Endoscopic resection is currently the treatment of choice for gastric epithelial tumours in Japan. Outside of Japan, this technique is increasingly gaining acceptance $(6,7)$. Endoscopic resection offers similar efficacy to surgery, and is also minimally invasive. Endoscopic resection for gastric tumours is superior to other treatments such as argon plasma coagulation therapy or photodynamic therapy because it enables complete pathological staging of the cancer after the procedure (8), which is critical because it allows for the stratification and refinement of further treatment (9). Compared with the risk of morbidity and mortality from surgery, EGC patients who are at no or lower risk for developing lymph node metastasis are ideal candidates for endoscopic resection (10).

EMR is recognized as an effective treatment for EGC. However, the standard EMR technique is usually inadequate for cancerous lesions larger than $20 \mathrm{~mm}$ in diameter. The local recurrence rates associated with incomplete EMR reported to date have been high (9\% to $18 \%$ ) (11). Incomplete resection leading to residual recurrent cancer in the stomach, therefore, continues to be a difficult problem.

ESD is superior to standard EMR because it can be accomplished easily using a standard single-channel gastroscope. ESD also has the advantage of achieving large en bloc resection, which enables precise histological staging, thereby potentially reducing disease recurrence compared with standard EMR methods. In the present study, the mean diameter of the resected specimens was $3.33 \mathrm{~cm}$ and the mean size of the tumours was $1.88 \mathrm{~cm}$. We confirmed that ESD can be used effectively to resect small superficial gastric lesions with a diameter of less than $2.0 \mathrm{~cm}$.

\section{TABLE 2}

Complications and local recurrence after endoscopic submucosal dissection $(n=120)$

\begin{tabular}{ll}
\hline Massive bleeding & $6(5.0)$ \\
Blood transfusion & $0(0)$ \\
Perforation & $3(2.5)$ \\
Emergent surgery & $3(2.5)$ \\
Local recurrent cancer & $2(1.67)$ \\
\hline
\end{tabular}

Data presented as $n$ (\%)

En bloc resection of gastric tumours is important. It was associated with lower local recurrence rates than piecemeal resection for gastric cancer. The en bloc resection rate in the present study was $90 \%$, which was slightly lower than the rate reported by Chang et al (12) (91.4\%). A possible reason for the lower en bloc resection rate was our inexperience in dealing with gastric tumours in difficult locations.

Of the 10 gastric tumours initially diagnosed as EGC on biopsy, four were found to be low-grade dysplasia and six were found to be high-grade dysplasia after resection and final pathological examination; two gastric tumours, initially diagnosed as high-grade dysplasia on biopsy, were found to be EGC after resection and final pathological examination. This could be explained by discrepancies in the definition of different degrees of dysplasia and carcinoma among various pathologists. Second opinions from other pathologists and unified pathological criteria to define dysplasia and carcinoma should, therefore, be considered and consensus reached before performing ESD. The indications for ESD should be re-emphasized and strictly adhered to by endoscopists and pathologists.

The rates of perforation $(2.5 \%)$ and bleeding $(5.0 \%)$ in the present study were lower than those reported in the study by Gotoda (13) (4\% and $7.0 \%$, respectively). This may have been due to the smaller sample size in our study. Whether intravenous proton pump inhibitors for the initial six days following ESD are beneficial in reducing the bleeding rate needs to be confirmed in a larger scale randomized study.

Apart from IT-ESD, there are other ESD techniques that have been described, including the hook knife (14), flex knife (15) and the knife in a small cap technique (16).

There were several limitations in the present study. First, the sample size was too small to draw firm conclusions. Second, ESD techniques require great skill - Gotoda et al (17) advised that a trainee requires at least 30 cases to gain early proficiency in this technique. Inexperienced endoscopists may be associated with a higher risk of procedure-related complications such as bleeding and perforation, as well as a higher risk of incomplete resection. Moreover, differences in the interpretation of histological results among different pathologists and/or between biopsy specimens before ESD and the en bloc tissue specimens after ESD will result in discrepancies.

\section{CONCLUSION}

ESD is a promising local curative treatment option for gastric epithelial tumours; however, it still carries the risks of perforation and bleeding. The education and training of endoscopists will improve the outcome of this procedure.

DISCLOSURE: Written consent was obtained from the patients or their relative(s) for publication of the patients' details.

\section{REFERENCES}

1. Ohkuwa M, Hosokawa K, Boku N, Ohtu A, Tajiri H, Yoshida S. New endoscopic treatment for intramucosal gastric tumors using an insulated-tip diathermic knife. Endoscopy 2001;33:221-6.

2. Rosch T, Sarbia M, Schumacher B, et al. Attempted endoscopic en bloc resection of mucosal and submucosal tumors using insulated-tip knives: A pilot series. Endoscopy 2004;36:788-801. 
3. Hirasaki S, Tanimizu M, Moriwaki T, et al. Efficacy of clinical pathway for the management of mucosal gastric carcinoma treated with endoscopic submucosal dissection using an insulated-tip diathermic knife. Intern Med 2004;43:1120-5.

4. Hirasaki S, Tanimizu M, Nasu J, Shinji T, Koide N. Treatment of elderly patients with early gastric cancer by endoscopic submucosal dissection using an insulated-tip diathermic knife. Int Med 2005;44:1033-8.

5. Japanese Gastric Cancer Association. Japanese classification of gastric carcinoma - 2nd English edition. Gastric Cancer 1998;1:10-24.

6. Rembacken BJ, Gotoda T, Fujii T, Axon AT. Endoscopic mucosal resection. Endoscopy 2001;33:709-18.

7. Soetikno RM, Gotoda T, Nakanishi Y, Soehendra N. Endoscopic mucosal resection. Gastrointest Endosc 2003;57:567-79.

8. Kitamura T, Tanabe S, Koizumi W, Mitomi H, Saigenji K. Argon plasma coagulation for early gastric cancer: Technique and outcome. Gastrointest Endosc 2006;63:48-54.

9. Hull MJ, Mino-Kenudson M, Nishioka NS, et al.

Endoscopic mucosal resection: An improved diagnostic procedure for early gastroesophageal epithelial neoplasms. Am J Surg Pathol 2006;30:114-8.

10. Ludwig K, Klautke G, Bernhard J, Weiner R. Minimally invasive and local treatment or mucosal early gastric cancer. Surg Endosc 2006;19:1362-6.
11. Oka S, Tanaka S, Kaneko I, et al. Advantage of endoscopic submucosal dissection compared with EMR for early gastric cancer. Gastrointest Endosc 2006;64:877-83.

12. Chang CC, Lee IL, Chen PJ, et al. Endoscopic submucosal dissection for gastric epithelial tumors: A multicenter study in Taiwan. J Formos Med Assoc 2009;108:38-44.

13. Gotoda T. Endoscopic resection of early gastric cancer: The Japanese perspective. Curr Opin Gastroenterol 2006;22:561-9.

14. Oyama T, Tomori A, Hotta K, et al. Endoscopic submucosal dissection of early esophageal cancer. Clin Gastroenterol Hepatol 2005;3(7 Suppl 1):S67-70.

15. Kodashima S, Fujishiro M, Yahagi N, Kakushima N, Ichinose M, Omata M. Endoscopic submucosal dissection for gastric neoplasia: Experience with the flex-knife. Acta Gastroenterol Belg 2006;69:224-9.

16. Yamamoto H, Kawata H, Sunada K, et al. Successful en bloc resection of large superficial tumors in the stomach and colon using sodium hyaluronate and small-caliber-tip transparent hood. Endoscopy 2003;35:690-4.

17. Gotoda T, Friedland S, Hamanaka H, Soetikno R. A learning curve for advanced endoscopic resection. Gastrointest Endosc 2005;62:866-7. 


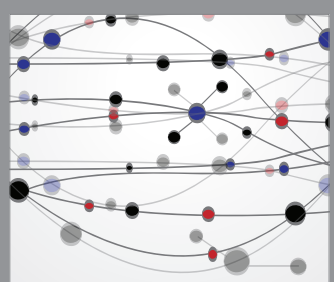

The Scientific World Journal
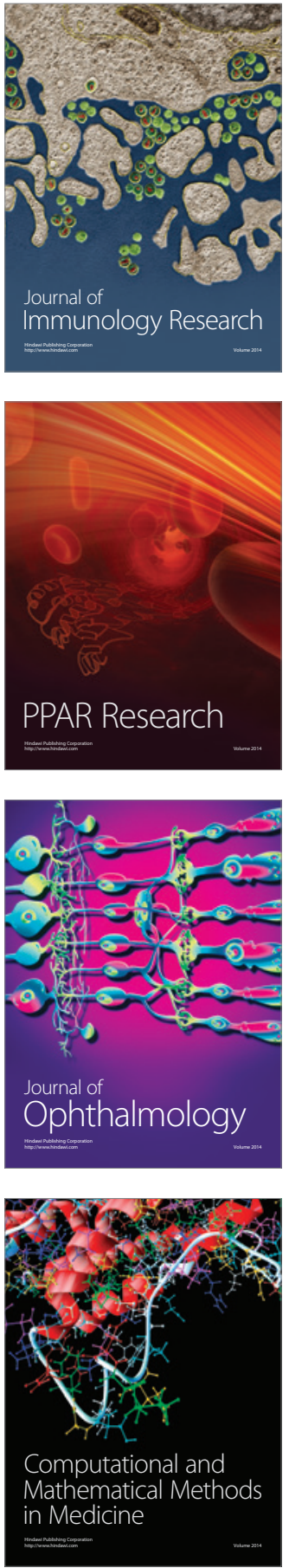

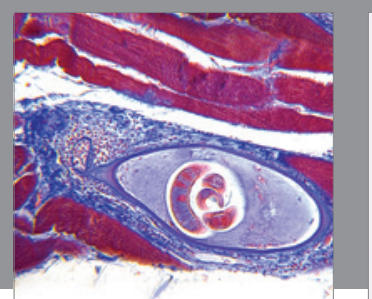

Gastroenterology Research and Practice

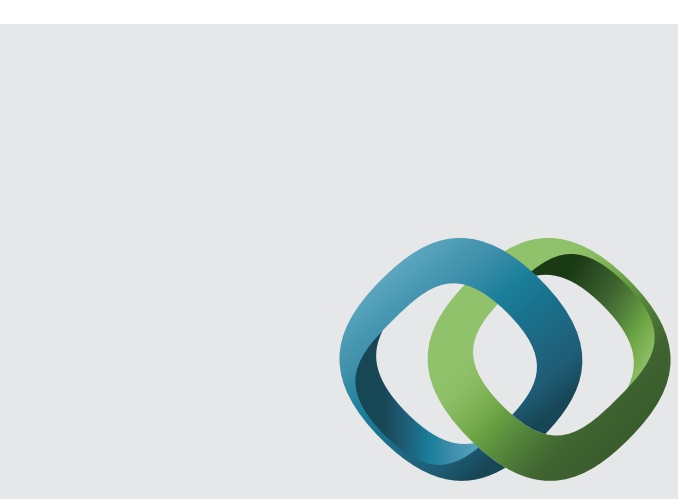

\section{Hindawi}

Submit your manuscripts at

http://www.hindawi.com
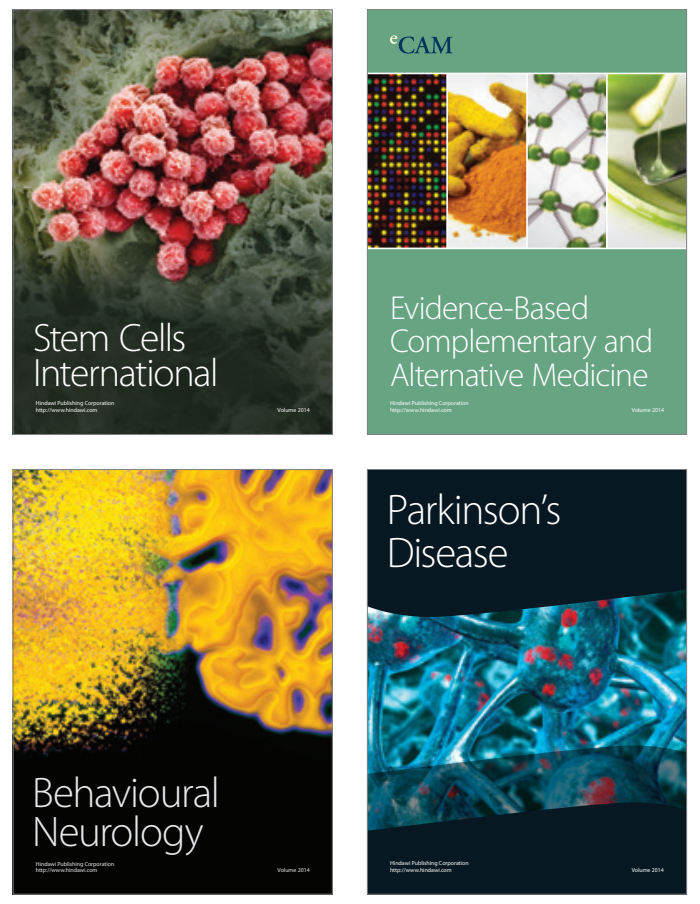
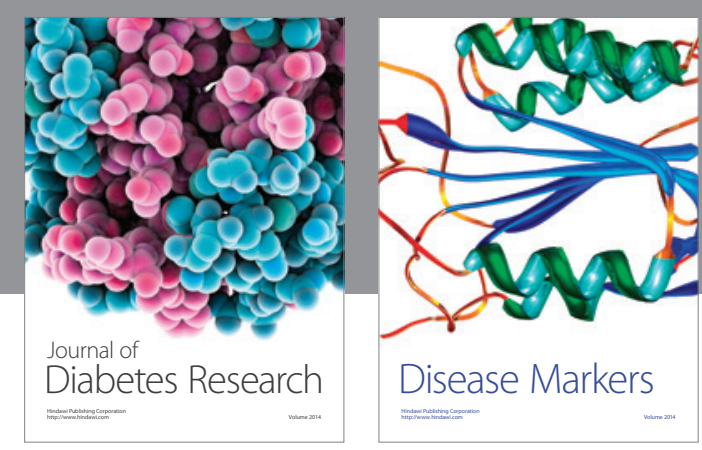

Disease Markers
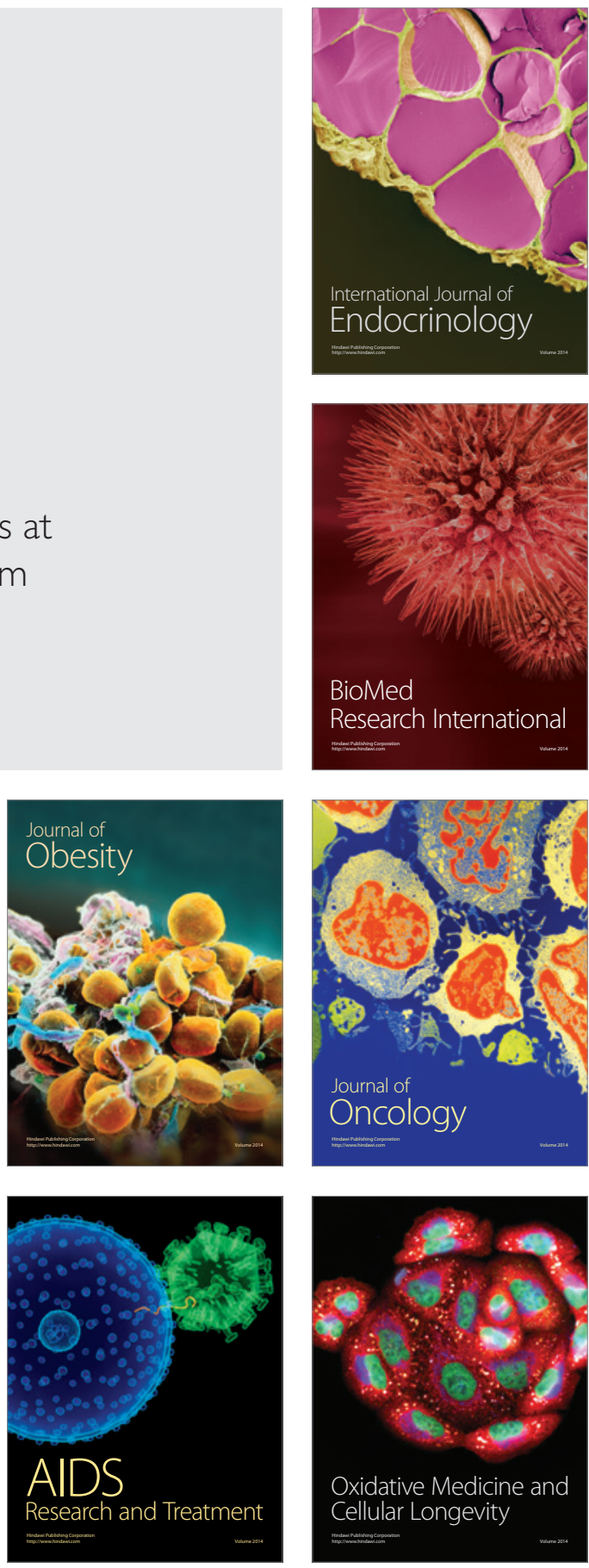